\title{
Effectiveness of Health Education Programmed on Knowledge regarding Management of Orthopedic Appliances among Fracture Patients at RL Jalappa Hospital, Kolar
}

\author{
G Vijayalakshmi* \\ Principal, Sri Devaraj Urs College of Nursing, Tamaka, Kolar, India
}

Received: 卧 June 15, 2018; Published: 卧June 22, 2018

*Corresponding author: G Vijayalakshmi, Principal Sri Devaraj Urs College of Nursing, Tamaka, Kolar, India

\begin{abstract}
Introduction: Effectiveness of health education programme was evaluated among forty patients diagnosed as having fracture and admitted at RLJH and RC with different types of orthopedic appliances.

Methodology: Using quasi experimental one group pre and post test design, patients were assessed for their knowledge followed by a health education programme was administered on management of orthopedic appliances among fracture patients. After seven days, a post test was conducted.
\end{abstract}

Findings: The results showed that structured health education programmed was effective in improving the knowledge score among fracture patients on management of orthopedic appliances.

Conclusion: Health professionals should spend some time with fracture patient to educate regarding orthopedic appliances and its related complications. So that, future occurrence of complications related to orthopedic appliances can be prevented.

Keywords: Knowledge; Health Education; Orthopedic Appliances; Fracture Patients

\section{Introduction}

Fracture is a disruption or break in the continuity of the bone. It usually occurs as a result of blow to the body, a fall, or accident. Traumatic injuries account the majority of the fractures, although some fractures are secondary to a disease (pathological fractures). The highest incidence of fracture in males is between the age group of 15 to 24 years and in women it is 65 years or above [1]. Majority of patients with injuries of the musculoskeletal system will be managed by bed rest, immobilization and rehabilitation itself without requirement of surgical intervention. Immobilization is achieved by orthopedic appliances. These appliances produce skeletal changes by applying force with the help of plaster cast and braces [2]. The patient with plaster cast may develop cast syndrome due to obstruction of superior mesenteric artery and it can be prevented if symptoms are recognized quickly and treatment instituted in a timely manner. Expected complications of plaster of Paris cast are impaired blood flow, nerve damage, tissue necrosis, infection, cast syndrome and also other complications may arise due to prolonged immobilization like hypostatic pneumonia, foot drop, renal calculi, stiffness of joints, constipation, pressure ulcer etc [3]. A study was conducted to assess the knowledge on fracture among 127 osteoporosis patients with recent fragility fracture at Hamilton Health Sciences hospital. The results showed that, majority of patients were unaware of important risk factors related to fracture. The study concluded that education initiatives are essential in improving knowledge among individuals in fracture clinics, acute care and rehabilitation settings, as these areas are an ideal place to communicate information [4]. Majority of musculoskeletal disorders are relatively long time in nature. The care and management of this condition needs a specialized orthopedic nursing practice5. After going through the related literature it was found that there were no studies either in India or abroad specifically related to management of orthopedic appliances. Hence the researcher felt with an objective to evaluate the effectiveness of structures health education programmed on management of orthopedic appliances among fracture patients. 


\section{Materials and Methods}

This study was based on Ludwig Von Bertalanff's general system theory. The design used for the study was quasi experimental one group pre test and post test. Based on the objectives of the study, a structured knowledge questionnaire and a lesson plan of health education on management of orthopedic appliances among the fracture patients was prepared in English and then it was translated to Kannada since the study participants communication and understanding were only in Kannada. Later the tool and health education lesson plan was validated by eight research and subject experts for its adequacy and appropriateness. After obtaining an ethical clearance from an institutional ethical committee, a written consent was obtained from the Medical Superintendent of RL Jalappa hospital and research centre, Tamaka, Kolar. After taking consent from the patients, through simple random sampling technique lottery method, 40 patients were selected who were diagnosed as having fracture and admitted to hospital with different orthopedic appliances, with the age group of 20 to 60 years, able to communicate with kannada or English language and willing to participate in the study. Patients who were critically ill, developed complications during the study period and mentally challenged were excluded from the study. Then the data was collected by using structured knowledge questionnaire on management of orthopedic appliances. Followed by on the same day, a health education on management of orthopedic appliances were administered using chart, flash card, pamphlet and OHP by individually and in groups. After seventh day, post test was conducted using same questionnaire. The data was collected from $26^{\text {th }}$ June 2014 to $30^{\text {th }}$ July 2014 in orthopedic wards.

\section{Results}

\section{Socio-demographic variables}

Table 1: The Socio-demographic variables of fracture patients.

\begin{tabular}{|c|c|c|}
\hline Variables & No of patients & Percentage \\
\hline Age in years & $15(20-30 \mathrm{yrs})$ & $37.5 \%$ \\
\hline Male & 22 & $55 \%$ \\
\hline Married & 28 & $70 \%$ \\
\hline Hindu & 28 & $70 \%$ \\
\hline Rural & 32 & $80 \%$ \\
\hline High school & 13 & $32.5 \%$ \\
\hline Joint family & 26 & $65 \%$ \\
\hline Coolie & 21 & $52.5 \%$ \\
\hline Income Rs. 5000/ month & 16 & $40 \%$ \\
\hline
\end{tabular}

Table 1 displays socio-demographic variables of fracture patients. The majority ( $37.5 \%$ ) of fracture patients in this study were in the age group of $20-30$ years and $30 \%$ of them with age group of 51-60 years, most(55\%) of them were males, $70 \%$ of them were married, $70 \%$ of them were Hindus, $80 \%$ of them were belong to rural area, $32.5 \%$ of them were studied up to high school, $65 \%$ of them were belong to joint family, $52.5 \%$ were coolie workers and $40 \%$ of fracture patients family income was below Rs.5000/month.

\section{Knowledge score of fracture patients}

Table 2: Area wise pretest mean Knowledge score distribution of fracture patients.

\begin{tabular}{|c|c|c|}
\hline Knowledge Area & Mean & SD \\
\hline Knowledge related to fracture & 2.67 & 1.68 \\
\hline $\begin{array}{c}\text { Knowledge related to orthopaedic } \\
\text { appliances }\end{array}$ & 4.42 & 2.40 \\
\hline Knowledge related to diet & 0.67 & 0.96 \\
\hline Knowledge related to activity & 1.02 & 0.68 \\
\hline Knowledge related to rest \& sleep & 0.4 & 0.62 \\
\hline Knowledge related to follow up & 0.8 & 0.74 \\
\hline Overall knowledge & 9.98 & 7.08 \\
\hline
\end{tabular}

After obtaining socio-demographic data, the fracture patients were assessed for their knowledge score on management of orthopedic appliances and presented in Table 2. Based on overall knowledge score obtained by fracture patients, they were grouped under inadequate knowledge (who scored below 50\%), moderately adequate knowledge (who scored 50 to $75 \%$ ) and adequate knowledge (who scored 76\% and above) and presented in Figure 1.

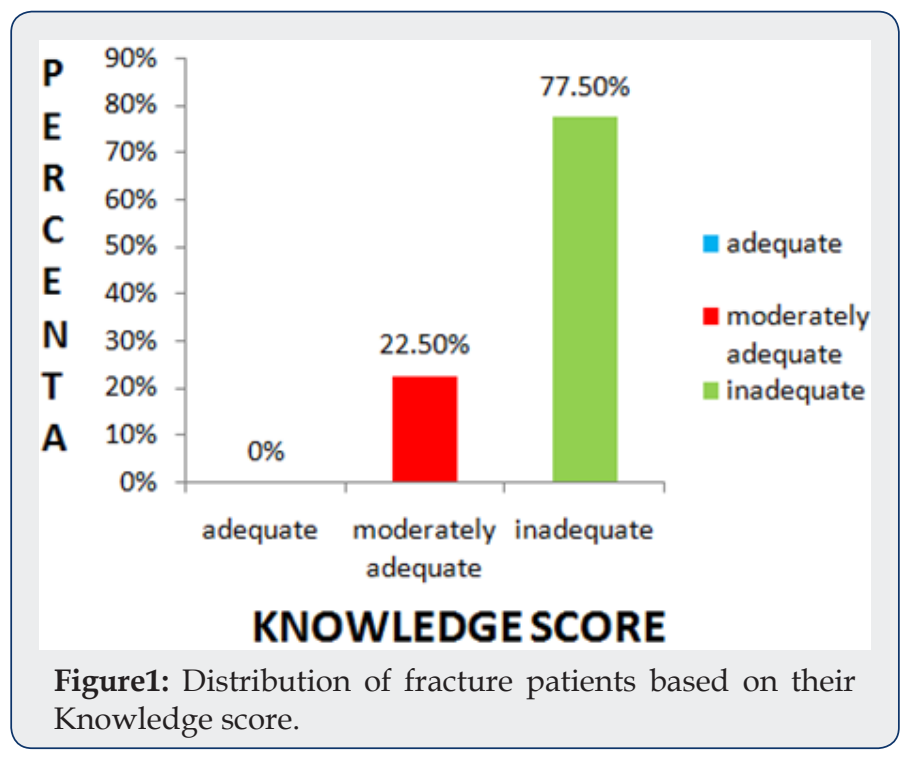

\section{Effectiveness of health education programmed in improving knowledge score}

After administering health education programmed, a post test was conducted to know the effectiveness of health education programmed on management of orthopedic appliances and the results revealed that, the pre test mean knowledge score was 10.37 
with SD of 4.58 where as the mean post test knowledge score was 17.37 with SD of 3.08, while enhancing the mean knowledge score of 7. The obtain t value was 3.01 which was significant at 0.05 level. This indicated that health education programmed was effective in increasing the knowledge score among fracture patients and the same was presented in Table 3.

Table 3: Comparison of overall pre and post test knowledge scores of fracture patients.

\begin{tabular}{|c|c|c|c|c|}
\hline Knowledge & Mean & SD & $\begin{array}{c}\text { Paired t } \\
\text { test }\end{array}$ & Inference \\
\hline Pre test & 10.37 & 4.58 & 3.01 & $\mathrm{~S}$ \\
\hline Post test & 17.37 & 3.08 & & \\
\hline
\end{tabular}

Association of knowledge score with selected sociodemographical variables

The association between post test knowledge score of fracture patients with selected socio demographic variables revealed that, there was no association between gender $\left(x^{2}=0.22\right)$, religion $\left(x^{2}=1.13\right)$, educational status $\left(x^{2}=0.02\right)$, type of family $\left(x^{2}=3.53\right)$, occupation $\left(x^{2}=3.52\right)$ and family income $\left(x^{2}=0.6\right)$ except age in years $\left(x^{2}=7.91\right)$ which was significant at 0.05 level.

\section{Discussion}

Knowledge regarding management of orthopedic appliances amongfracture patients isvery essential in preventing complications. Hence the study was undertaken to assess the effectiveness of health education programme on knowledge regarding management of orthopedic appliances among fracture patients and the results showed that, with regard to socio-demographic variables, majority $(37.5 \%)$ of them were in the age group of $20-30$ years and most (55\%) of them were males which was contradicted by the study conducted by Swati Kambli [6]. Related to knowledge score, the mean pre test knowledge score was 10.37 with SD of 4.58 where as the mean post test knowledge score was 17.37 with SD of 3.08, while enhancing the mean knowledge score of 7 , indicating that health education programme was effective in improving knowledge score among fracture patients and this was supported by the study conducted by Saccone M, Jain AK [7]. With regard to association of knowledge score with selected socio-demographic variables, it was found that there was no association between knowledge with selected socio demographic variables except age.

\section{Limitations}

The study was limited to fracture patients admitted at RL Jalappa Hospital and Research centre, with different orthopedic appliances.

\section{Conclusion}

The present study concludes that, structured health education programme was effective in improving the knowledge score among fracture patients on management of orthopedic appliances.

\section{Acknowledgement}

Researcher expresses her sincere gratitude to all fracture patients who participated in the study and authorities of RL Jalappa hospital for granting permission to conduct the study.

\section{References}

1. J Maheshwari (2005) Essential orthopedics ( $3^{\text {rd }}$ edn.), Mehta publishers, New Delhi, India.

2. John DM, Steward (2003) Traction and Orthopedic appliances ( $1^{\text {st }}$ edn.), Churchill Livingstone Pvt Ltd, New Delhi, India.

3. Suzanne C, smeltza and Brenda (1999) Text book of medical surgical Nursing. $8^{\text {th }}$ edn. Philadelphia: Lippincott Company publications 1852.

4. L Giangregorio (2010) Osteoporosis Knowledge among individuals with recent fragility fracture. Ortho Nurs 29(2): 99-107.

5. (2007) WHO Road Accidents.

6. Swati Kambli (2014) Fractured patient knowledge regarding care and treatment. International Journal of science and research 3(7): 11781181.

7. Saccone M, Jain AK (2009) Fracture healing in India: Available therapies, indications, and protocols. Indian J Orthopaedics 43(2): 175-181.
This work is licensed under Creative Commons Attribution 4.0 License

To Submit Your Article Click Here: Submit Article

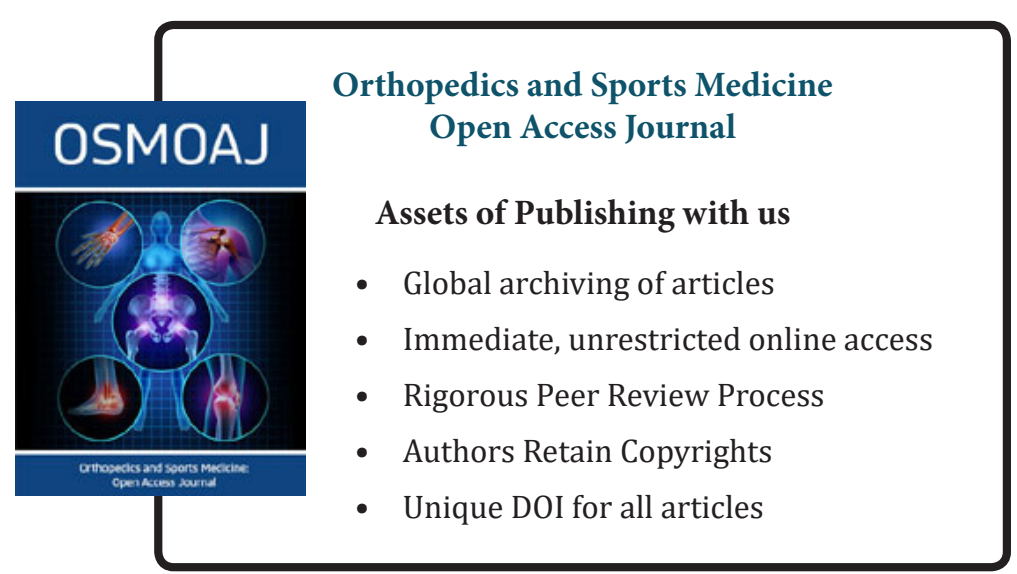

